\title{
It's time to move away from fee-for-service
}

\section{Louis Wang and Qinya Zhang}

\author{
Simon Fraser University
}

Compensation paid to physicians accounts for the third largest share of total healthcare spending in Canada, behind hospitals and pharmaceuticals. ${ }^{1}$ As one of the fastest-growing health categories in recent years, physician services cost more than $\$ 29$ billion annually, representing $14.6 \%$ of total healthcare spending in $2011 .{ }^{1}$ For fiscal $2011 / 12$ alone, the increase in payments made to fee-forservice physicians rose $7.1 \%$. This increase can be reduced by changing the mechanism of the payment method.

The dominant form of payment received by Canadian physicians is fee-for-service. ${ }^{2}$ This is a payment method in which the amount of compensation received is proportional to the number of services provided. The important advantage of fee-for-service lies in its economic principle to price services discretely and motivate the provider to meet patients' demands. Unfortunately, given the direct link between providing service and receiving remuneration, fee-for-service can be problematic on several fronts. The main problem is that physicians are motivated to overtreat patients and deliver services in the shortest amount of time possible in order to maximize profit. ${ }^{3}$ When payment depends on the quantity rather than quality of services provided, the effort put into important nonclinical responsibilities is reduced, such as administrative, educational, or communicative tasks, including those related to health promotion and preventive care. ${ }^{4}$ Physician payment mechanisms act as a logical entry point for cost containment and present additional opportunities to affect better integration, coordination, and multidisciplinary care.

There is a need to move away from fee-for-service payments, but doing so is a challenge. Fee-for-service is the preferred payment method model for the majority of physicians and medical associations even prior to publically-funded health care systems. ${ }^{5}$ The fees charged by physicians are set by negotiation between medical associations and provincial governments, but government can only influence the average level of fees while the relative prices of fees are set internally by medical associations. ${ }^{4}$ Without direct control over the pricing of medical services, governments have moved from controlling fees to controlling the incomes of physicians through adjusting aggregate payout based on previous years' volumes or through establishing individual income ceilings. ${ }^{4}$ Critics of fee-for-service argue that alternative payment methods may address government fiscal objectives while simultaneously providing better healthcare quality and promoting more efficient usage of resources. ${ }^{4}$

There are multiple alternative payment methods currently in use, each having potential advantages. ${ }^{6}$ Salary, sessional, and hourly fees are paid based on units of time rather than on quantity of services provided. These payment methods can eliminate adverse incentives for patient-selection (choosing patients with the greatest bang for buck) and over-treatment, but at the potential cost of reducing physician productivity and efficiency. ${ }^{7}$ Capitation fees are lump-sum payments determined by the number of rostered patients. Its key advantages include reducing over-treatment, incentivizing preventive care, and increasing the number of patients serviced. For the government, a capitation arrangement would make health care expenditures more predictable because cost would be characterized by population demographics. ${ }^{4}$ However, patient-selection and unnecessary referrals to specialists may persist depending on how capitation is implemented. ${ }^{4,7}$ Performance-based payments are another alternative method where bonuses are rewarded for achieving a pre-determined goal. This method can be used to recruit physicians to work in remote communities or to target specific health outcomes in underserved areas. ${ }^{3}$ In each of these schemes, different aspects of health care goals are incentivized which may work for or against the providers' and patients' interests. In principle, alternative payment methods appear to better align the needs of both parties. 
The evidence for alternative payments in reducing healthcare costs is not definitive. When the Health Services Organization (HSO) experimented with capitation payment in 1973, they did not see a reduction in cost or an improvement in quality of healthcare services. ${ }^{8}$ However, another study found that physicians paid through capitation that is privately funded did reduce healthcare costs, although this was complemented with patient and provider dissatisfaction. ${ }^{9}$ In a review article, the authors found that salary payments reduced healthcare costs associated with lower volumes of consultations, lower levels of hospital use, and fewer tests and X-rays. ${ }^{10}$ Research on alternative payment methods is difficult to conduct. The inability to associate health outcomes with payment methods and the inability to compare settings across contextual boundaries makes it difficult to study the implications of cost containment alone.

In our opinion, the financial incentives embedded in feefor-service are too high to adequately align patient and provider interests. Alternative payment methods offer a reasonable approach to curb rising healthcare costs. While the current healthcare system emphasizes the importance of physicians, the discussion on physician payment should also engage other healthcare providers. Changing the method of payment presents an opportunity to address the financial incentives in fee-for-service on physician practice.

\section{References}

1. National Health Expenditure Trends, 1975 to 2013 [Internet]. Canadian Institute for Health Information; 2012 [cited 2014 February 2]. Available from: http://www.cihi.ca

2. National Physician Database, 2011 - 2012 Data Release [Internet]. Canadian Institute for Health Information; 2013 [cited 2014 March 19]. Available from: http://www.cihi.ca

3. Alternative Payment Models to Fee for Service [Internet]. Canadian Medical Association; 2005 [cited 2014 March 19]. Available from: http://www.cma.ca

4. Emery JH, Auld C, Lu M. Paying for physician services in Canada: the institutional, historical and policy contexts-Part 1 of Incentive Effects of Physician Remuneration Schemes. Alberta: Institute of Health Economics; 1999. Institute of Health Economics Working Paper, No. 99-6.

5. Myth: Most Physicians Prefer Fee-For-Service Payment [Internet]. Canadian Foundation for Healthcare Improvement; 2010 [cited 2014 February 2]. Available from: http://www.cfhi-fcass.ca

6. Wranik DW, Durier-Copp M. Physician Remuneration Methods for Family Physicians in Canada: Expected outcomes and Lessons Learned. Health Care Anal. 2010;18(1):35-59.

7. Roberts MJ, Hsiao W, Berman PA, Reich MR. Getting Health Reform Right: A Guide to Improving Performance and Equity. New York: Oxford University Press; 2004

8. Gillett J, Hutchison B, Birch S. Capitation and primary care in Canada: financial incentives and the evolution of health service organizations. Int J Health Serv. 2001; 31(3):583-604

9. Mongan JJ, Ferris TG, Lee TH. Options for Slowing the Growth of Health Care Costs. N Engl J Med. 2008;358(14):1509-14.

10. Gosden T, Pedersen L, Torgerson D. How should we pay doctors? A systematic review of salary payments and their effect on doctor behaviour. An Int J Med. 1999;91 (1):47-55.
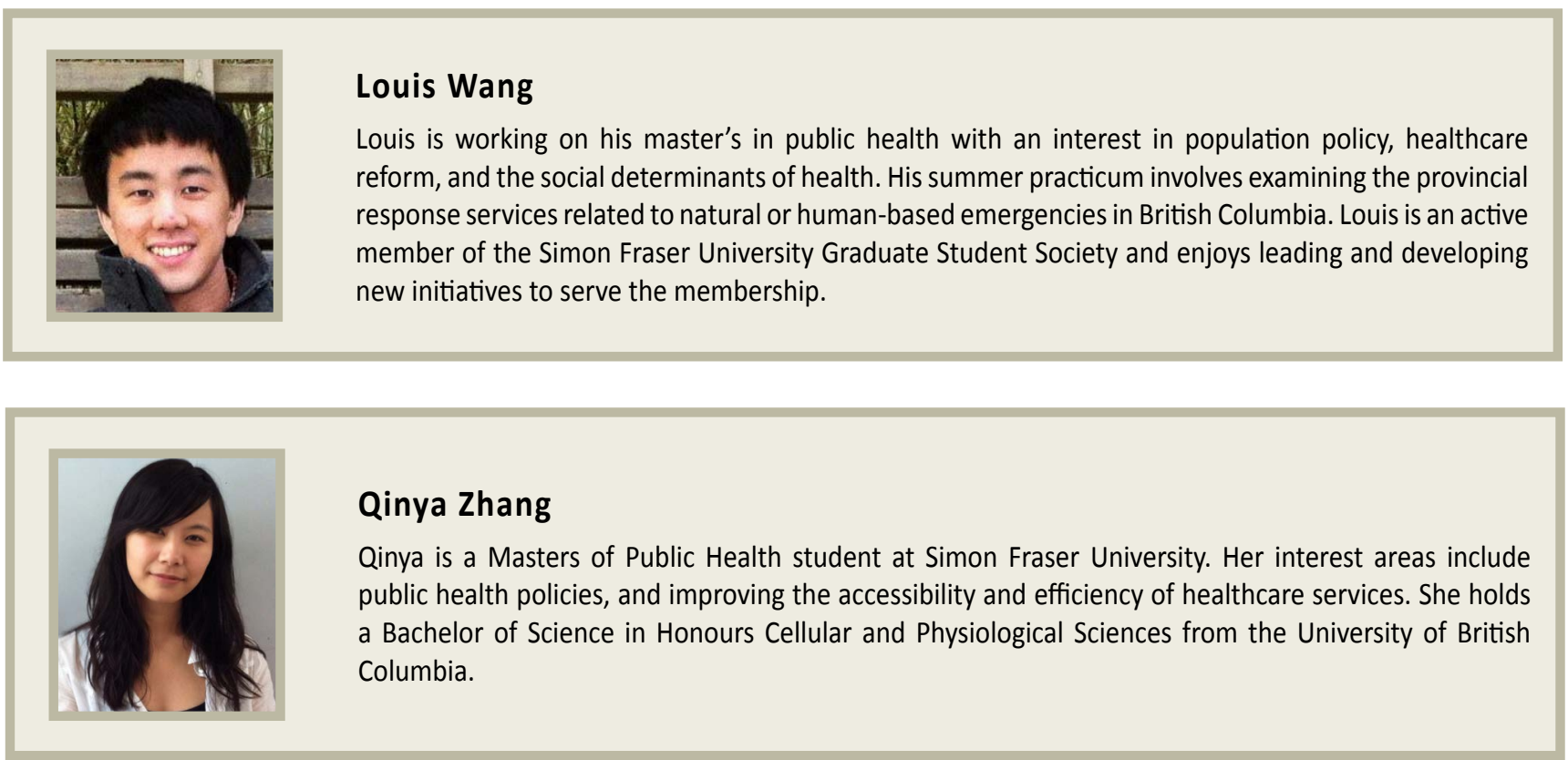